Investigations

\title{
Comparison of Green Roof Model Predictions with Experimental Data
}

\author{
${ }^{1,2}$ Sergio Quezada-García, ${ }^{1}$ Manuela Azucena Escobedo-Izquierdo, ${ }^{2}$ Juan José Ambriz-García, \\ ${ }^{2}$ Rodolfo Vázquez-Rodriguez and ${ }^{3}$ Diego Morales-Ramírez \\ ${ }^{1}$ Facultad de Ingeniería, Universidad Nacional Autónoma de D.F. México \\ ${ }^{2}$ División de Ciencias Básicas e Ingeniería, Universidad Autónoma Metropolitana-Iztapalapa, D.F. México \\ ${ }^{3}$ Facultad de Arquitectura, Universidad Nacional Autónoma de México, D.F. México
}

Article history

Received: 20-09-2014

Revised: 07-11-2014

Accepted: 10-07-2015

Corresponding Author: Sergio Quezada-García, Facultad de Ingeniería,

Universidad Nacional

Autónoma de D.F. México

Email: sequga@gmail.com

\begin{abstract}
In this study, the results of a green roof model are presented and compared with experimental data. Good agreement between simulation and experiment were found for different experimental conditions that were carried out in a controlled environment laboratory. The study of green roof heat transfer processes is important because it allows a better thermal design in buildings; the use of urban forest area reduces the urban heat island effect and others improvements such as air purification. Also, with a mathematical model that accurately describes the heat transfer in the green roof it is possible to determine variables such as the local and averaged temperature inside the building and thus obtain the energy savings of a green roof over a conventional one. In this study a mathematical model of heat transfer in a green roof considers that porous materials form some of its layers and that the heat sources are introduced into the model through boundary conditions. In order to validate the mathematical model considering porous materials, the data obtained from the model and laboratory experimental data were compared. The results show that the inclusion of equations considering porous materials, inside the heat transfer model of the green roof, described properly heat transfer processes. Considering porous materials in the green roof model allows including effects due to canopy density, the amount of water contained in the soil layer or penetration of the radiation through the green layer.
\end{abstract}

Keywords: Green Roof, Heat Transfer, Porous Media, Experimental Data, Mathematical Model

\section{Introduction}

Many studies about Green Roofs System (GRS) have been made in recent years due to the multiple benefits that they offer, such as increase in urban forest area (Berndtsson et al., 2009), air purification (Yang et al., 2008; Li et al., 2010), reducing runoff Mentens et al., 2006; Berndtsson et al., 2009; Stovin et al., 2012; Speak et al., 2013), reduction of the urban heat island effect (e.g., Wong et al., 2003; Weng and Yang, 2004; Wong and Chen, 2005; Takebayashi and Moriyama, 2007; Lin et al., 2008; Santamouris, 2012; Wong and Lau, 2013), life extension of the roof (e.g., Saiz et al., 2006; Kosareo and Ries, 2007; Clark et al., 2008), reducing the acoustical noise (e.g., Renterghem and Botteldooren, 2009), preservation of biodiversity (e.g., Madre et al., 2013) and energy saving in the building (e.g., Onmura et al., 2001; Theodosiou,
2003; Castleton et al., 2010; Zinzi and Agnoli, 2012, Hong et al., 2012; Chan and Chow, 2013).

Benefits, such as energy saving in the building and reducing the effect of urban heat island are examples of how the GRS alters the balance of energy in the roof (Sailor and Hagos, 2012). In order to quantify the energy savings in the building, equations are needed to describing accurately the heat transfer through the different layers comprising at GRS.

Early efforts of modeling GRS represented the green roof as a simple resistive layer whose thermal conductivity was essentially constant (Niachou et al., 2001). In recent years, sophisticated models for the energy balance in GRS have been developed (Sailor, 2008). Other models are: The model proposed by Del Barrio (1998), the model of Ayata et al. (2011), which considers four terms in the energy balance; heat gain due to net radiation, the sensible heat flux, the solid heat flux 
and the latent heat flux. And the model proposed by Kumar and Kaushik (2005).

Sailor (2008) proposed a more complete model, however, this model does not take into account the metabolic processes of plants such as photosynthesis and respiration, to name a few. The model proposed by Feng et al. (2010) includes in the energy balance the effects due to photosynthesis and plant respiration.

In previous works the heterogeneous effects of the green roof are not explicitly considered. In this study the heat transfer process in the green roof was consider as energy transport in porous media. The modeling results for heat transfer in a green roof are presented and compared with experimental data. Good agreement between simulation and experiment were found for different experimental conditions that were carried out in a controlled laboratory environment.

\section{Mathematical Model}

The energy balance model for GRS proposed by Feng et al. (2010) is based on the following assumptions:

- The lawn, with $100 \%$ leaf coverage, is considered as a diffuse gray body

- Thermal effects of plants metabolism except for photosynthesis, respiration and transpiration and thermal effects of microorganism in the soil are negligible

- The conditions with precipitation and dew are not included

- The GRS is large enough to assume horizontal homogeneity and apply a one-dimensional (vertical) analysis

Considering plants and soil as the system, structural roof and ambient air as the environment, the energy exchanges between the plants-soil system and the environment are obtained and illustrated in Fig. 1. According to the first law of thermodynamics, the following energy balance equation is obtained Equation 1:

$$
\begin{aligned}
& q_{s r}+q_{l r}+q_{c v}+q_{e m}+q_{t p}+q_{e p}+ \\
& q_{s p}+q_{s s}+q_{t r}+q_{p s}+q_{r p}=0
\end{aligned}
$$

where, $q_{s r}$ is the heat gain from solar radiation, $q_{l y}$ the heat gain from long-wave radiation, $q_{c v}$ the heat transferred by convection, $q_{e m}$ the heat loss by emission, $q_{t p}$ the heat loss by transpiration, $q_{e p}$ the heat loss by evaporation, $q_{s p}$ the heat storage by plants, $q_{s s}$ the heat storage by soil, $q_{t r}$ the heat transferred into the room, $q_{p s}$ the solar energy converted by photosynthesis and $q_{r p}$ the heat generation by respiration.

The heat gain from solar radiation in the GRS is calculated by (Jim and Tsang, 2011) Equation 2: $q_{s r}=q_{s r i} \alpha_{s}$

where, $q_{s r i}$ is the incident solar radiation and $\alpha_{s}$ is the short-wave absorptivity of the lawn.

The heat gain from long-wave radiation is calculated by (Meng and $\mathrm{Hu}, 2005)$ Equation 3:

$$
q_{l r}=\alpha_{l} \sigma\left(T_{a}+273.15\right)^{4}\left(0.802+0.004 T_{d}\right)
$$

where, $\alpha_{l}$ is the long-wave absorptivity of the lawn, $\alpha$ is Stefan-Boltzmann constant, $T_{a}$ is ambient air temperature in ${ }^{\circ} \mathrm{C}$ and $T_{d}$ is dew point.

Many authors have dedicated their studies to propose a suitable method for the calculation of heat transferred by convection. Some authors have used Newton's law of cooling with minor modifications (e.g., Meng and $\mathrm{Hu}$, 2005; Denardo, 2003; Jensen et al., 1990). Some other authors have used a term called Leaf Area Index (LAI) (e.g., Niachou et al., 2001; Tabares-Velasco and Srebric; 2009; Deardorff, 1978; Ayata et al., 2011) that is defined as the total, one-sided area of leaves per unit ground surface area.

In this study is used the method developed by (Feng et al., 2010 Equation 4):

$q_{c v}=(5.7+3.8 v)\left(T_{p}-T_{a}\right)$

where, $v$ is wind speed and $T_{p}$ is the plant temperature.

Heat loss by emission can be calculated by (Jim and Tsang, 2011) Equation 5:

$q_{e m}=\sigma \varepsilon\left(T_{p}+273.15\right)^{4}$

where, $\varepsilon$ is the emissivity of the lawn.

The heat loss by transpiration and evaporation can be simplified in one equation, so the heat loss by evapotranspiration is given by (Feng et al., 2010) Equation 6:

$q_{e t}=R_{e l} l$

where, $R_{e t}$ is the evapotranspiration rate and $l$ is latent heat of vaporization.

The heat storage by plants is given by (Feng et al., 2010) Equation 7:

$q_{s p}=\rho_{p} C p_{p} \frac{d T_{p}}{d t}$

where, $\rho_{p}$ is the areal density of plants, $C_{p p}$ is the specific heat of plants and $t$ is the time.

Similarly, Feng et al. (2010) proposed calculating the heat storage by soil with Equation 8:

$q_{s s}=\rho_{s} C p_{s} \frac{d T_{s}}{d t}$ 


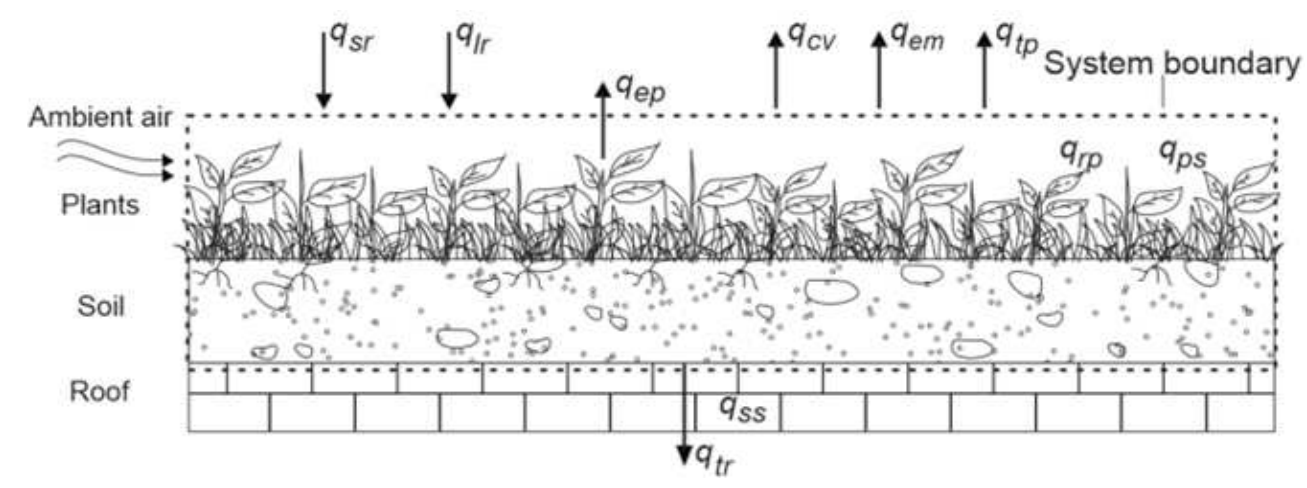

Fig. 1. Energy exchange a GRS and its environment (Feng et al., 2010)

The energy converted by photosynthesis and heat generation by respiration, if these two heat sources are added, is an equation used to determine the net heat converted by photosynthesis (Feng et al., 2010) Equation 9:

$$
q_{p s, n e t}=\Delta_{r} H_{m}^{\theta}\left(25^{\circ} C\right) \frac{v_{n e t,} C_{6} H_{12} O_{16}}{M_{C_{6} H_{12} O_{6}}}
$$

where, $v_{\text {net }}, \mathrm{C}_{6} \mathrm{H}_{12} \mathrm{O}_{16}$ is the net photosynthetic rate (in glucose), $\Delta_{r} H_{m}^{\theta}\left(25^{\circ} \mathrm{C}\right)$ is standard molar enthalpy of reaction at $25^{\circ} \mathrm{C}$ and $M_{C 6} H_{12} O_{6}$ is the glucose molar mass.

However the soil is a porous material and the composite layer by plants also can be considered a porous material because there is air between the plants. The Equation 9 and 10 in the Feng et al. (2010) do not take into account these considerations.

\section{Porous Medium Approach}

In this section the equations for porous media or twophase media approach are presented.

The Fig. 2 illustrates how a material appears to be homogeneous on a large-scale and heterogeneous or a porous material on a smaller-scale. This is the case of the soil layer that is formed mainly by land and water. A similar case is given in the green layer that is composed by plants and air around them.

Starting from a local-instantaneous formulation, the equations for two-phase media can be derived. In the case of the soil layer the equations are given by Equation 10 and 11 :

$$
\begin{aligned}
& (\rho C p)_{\ell} \frac{\partial T_{\ell}}{d t}=k_{\ell} \nabla^{2} T_{\ell}+q_{\ell}^{\prime \prime} \\
& (\rho C p)_{w} \frac{\partial T_{w}}{d t}=k_{w} \nabla^{2} T_{w}+q_{w}^{\prime \prime}
\end{aligned}
$$

where, subscript $\ell$ refers to the land and the subscript $w$ refers to water; $q$ "' is heat source.
By an appropriate mathematical treatment it is possible to relate the Equation 10 and 11 for proposing an equation valid for a porous media with heat transfer (Espinosa-Paredes et al., 2013) Equation 12:

$$
(\rho C p)_{s} \frac{\partial\langle T\rangle}{\partial t}=\nabla \cdot\left(K_{s} \cdot \nabla\langle T\rangle\right)+\varepsilon_{\ell}\left\langle q^{\prime \prime \prime}\right\rangle^{\ell}
$$

where, \langle\rangle indicates average amounts, the subscript $s$ indicate effective properties for the soil layer and $\varepsilon_{\ell}$ is the volume fraction of land in the soil layer. This equation is based on scale length restrictions, which is widely discussed in Espinosa-Paredes (2010; 2012).

The effective properties for the soil layer are given by Equation 13 and 14:

$$
\begin{aligned}
& (\rho C p)_{s}=\left(\rho_{\ell} C p_{\ell} \varepsilon_{\ell}+\rho_{w} C p_{w} \varepsilon_{w}\right) \\
& K_{s}=\left(k_{\ell} \varepsilon_{\ell}+k_{w} \varepsilon_{w}\right)
\end{aligned}
$$

It is important to note that these effective properties include the effect of the properties of land and water in the heat transfer through the soil layer. The effective properties are affected by the amount of land and water in the soil layer.

Similarly it is possible to obtain an equation valid for the green layer that considers plants and air:

$$
(\rho C p)_{g} \frac{\partial\langle T\rangle}{\partial t}=\nabla \cdot\left(K_{g} \cdot \nabla\langle T\rangle\right)+\varepsilon_{p}\left\langle q^{\prime \prime \prime}\right\rangle^{p}
$$

where, the subscript $g$ indicates the effective properties for the green layer and $\varepsilon_{p}$ is the volume fraction of the plants. The full mathematical development for Equation 12 and 15 is presented in Appendix A.

In the next section it is presented the complete mathematical model for the heat transfer process through a green roof, GRS, which includes the effect of porous materials. 


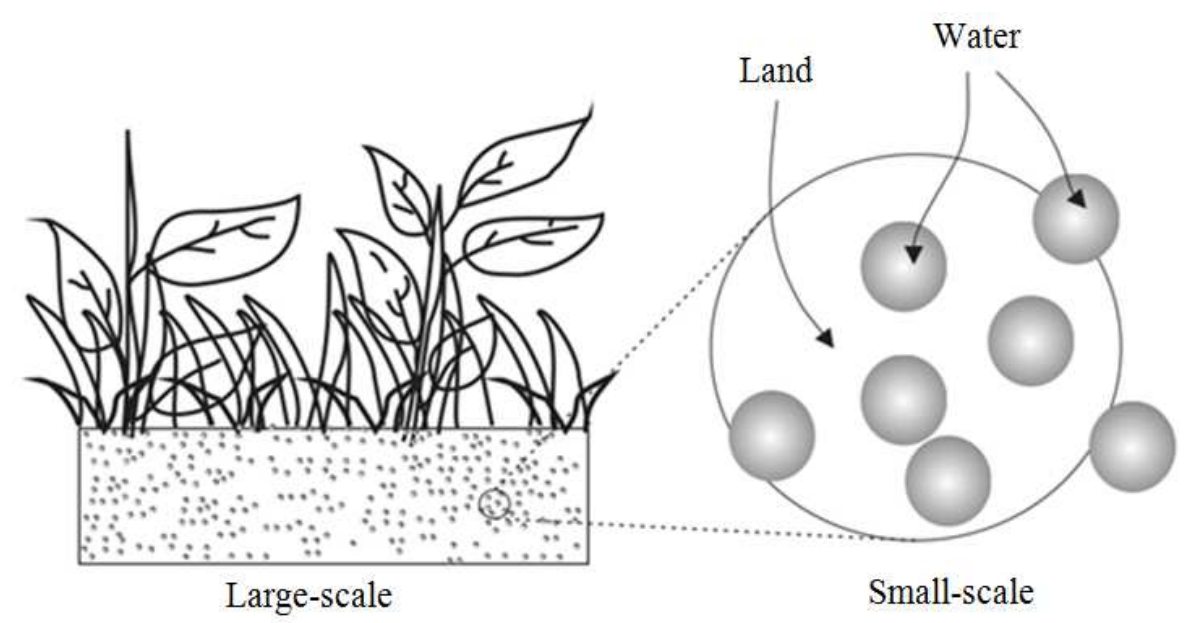

Fig. 2. Soil layer at different length-scales

\section{Complete Mathematical Model}

In this section it is presented the heat transfer model for green roofs considering that some of the component layers are porous materials.

The heat transfer in a green layer formed mainly by plants and air is given by:

$(\rho C p)_{g} \frac{\partial\langle T\rangle_{g}}{\partial t}=\nabla \cdot\left(K_{g} \cdot \nabla\langle T\rangle_{g}\right)$

In Equation 16 are not included heat sources. A way to easily include the effect of heat sources is through the use of the following boundary condition that is valid in the interface formed by green layer and environment:

$-K_{g} \frac{d\langle T\rangle_{g}}{d x}=\sum q^{\prime \prime}$

where, the term on the right side of the equation is given by Equation 18:

$$
\begin{aligned}
\sum q^{\prime \prime} & =q_{s r}+q_{l r}+q_{c v} \\
& +q_{e m}+q_{e t}+q_{p s, n e t}=0
\end{aligned}
$$

The heat transfer in the soil layer formed mainly by land and water is given by Equation 12, without effect of heat sources that may be reaching the soil layer, such as solar radiation and long-wave radiation, these effects could be included by posing appropriate boundary condition.

Equation 12 and 16 are related by the following boundary condition and valid for all times:

$$
\langle T\rangle_{g}=\langle T\rangle_{s}
$$

The Equation 19 is valid on the interface formed by the green layer and the soil layer.

In addition the heat transfer through the building material is given by Equation 20:

$(\rho C p)_{b} \frac{\partial T_{b}}{\partial t}=k_{b} \frac{\partial^{2} T_{b}}{\partial x^{2}}$

where, subscript $b$ indicates effective building properties.

At the interface formed by the construction material and the soil layer the following boundary condition is valid Equation 21:

$T_{b}=\langle T\rangle_{s}$

The boundary condition between the material construction element and the inside of building is given by Equation 22:

$-k_{b} \frac{d T_{b}}{d x}=h\left(T_{b}-T_{r}\right)$

where, $T_{r}$ is the room temperature or the temperature inside the building.

The set of equations 16 to 22 represents a new model for the heat transfer process throughout the green roof.

\section{Materials and Methods}

In order to validate the inclusion of Equation 12 and 15 in the model to calculate the heat transport through the soil layer and through the green layer, an experimental model was designed. The Controlled Environment Laboratory (CEL) of the Universidad Autónoma MetropolitanaIztapalapa (Arroyo-Cabañas et al., 2009), was used for monitoring several experimental scenarios of a green roof scale model. 


\section{Laboratory}

The CEL is a laboratory consisting of two chambers, thermally insulated, which contain a number of thermistors to monitor the temperature at all times, the CEL also has a control room where through computer equipment and specially designed software it is controlled and monitored the temperature of the thermistors in the two chambers. In this way the temperature inside the two chambers can be controlled and kept constant; the lower limit is 15 and $40^{\circ} \mathrm{C}$ is upper limit temperature.

\section{Equipment and Materials}

The experimental model is a wood parallelepiped with a square base. With dimensions of $20 \mathrm{~cm}$ at the base and total height of $35 \mathrm{~cm}$; has no caps and has a zone division ata height of $15 \mathrm{~cm}$. The walls are thermally isolated using glass wool and expanded polystyrene to ensure that heat transfer takes place preferably in the vertical direction.

In the lower zone there is a thermistor and at the top of the higher zone there is another thermistor; inside the higher zone there are 5 thermistors every $5 \mathrm{~cm}$; this is illustrated in Fig. 3.

\section{Experiment}

The ice was placed in the lower zone of the parallelepiped with the purpose of having a cold constant temperature while the laboratory was programmed at a warm temperature. The parallelepiped is filled with soil to monitor the change in temperature at different heights and at different times, as is illustrated schematically in Fig. 3.

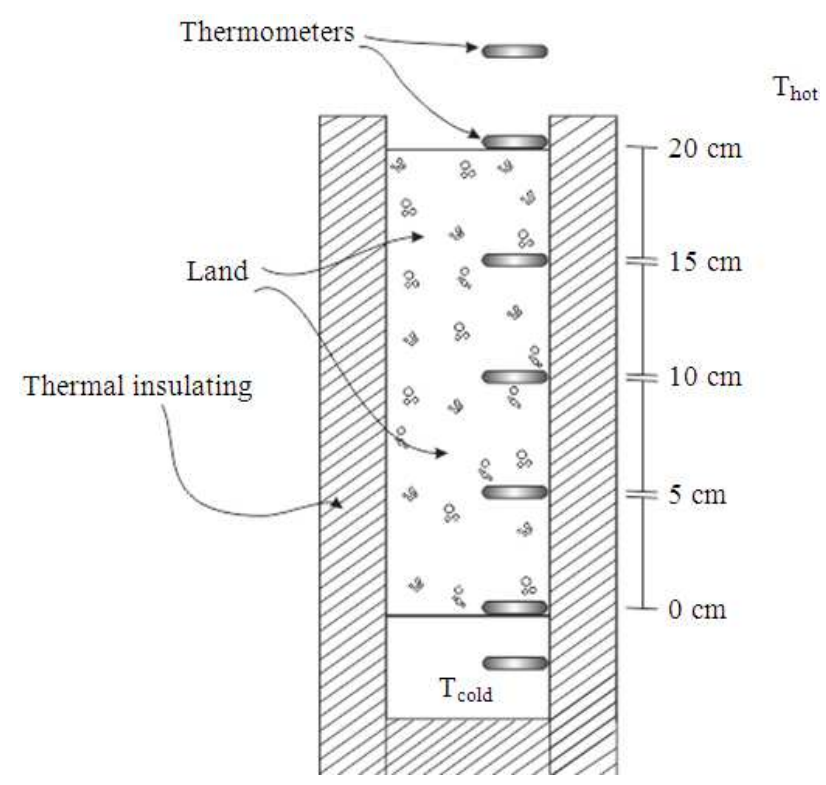

Fig. 3. Experimental model in Controlled Environment Laboratory (CEL)
During the experiment it was kept a constant cold temperature inside the experimental model and a hot temperature in the CEL in order to achieve a temperature gradient. Then the temperature was monitored on the soil until reaching the steady state.

\section{Measurements}

In order to determine if the mathematical model that includes expressions for the heat transfer through porous materials provides results comparable to those that would have in a green roof, the temperature of the soil as a function of distance and time in the presence of a temperature gradient was determined experimentally. Temperature at different distances is recorded every minute until reaching the steady state.

\section{Comparisson Model}

In this study the comparison of two experiments performed under different conditions of temperature is shown.

In the first case the laboratory temperature (warm temperature) was programmed at $35^{\circ} \mathrm{C}$ while the temperature inside the experimental model, i.e., the cold temperature was maintained around $12^{\circ} \mathrm{C}$. These conditions were maintained about six hours and the results obtained are shown in Fig. 4.

Comparing the experimental data with the data obtained using the mathematical model simulation indicates that both curves show the same tendency.

Experimental data and simulation results obtained in the steady state are shown in Table 1. The maximum relative error obtained in this case is $13.81 \%$ at $15 \mathrm{~cm}$ distance, this may be because the soil properties are not uniform and change when approaching the interface.

In the second case the laboratory temperature (warm temperature) was programmed at $32^{\circ} \mathrm{C}$ while the temperature inside the experimental model, i.e., the cold temperature was maintained around $10^{\circ} \mathrm{C}$. About six hours these conditions were maintained, the results obtained are shown in Fig. 5.

Experimental data and simulation results obtained in the steady state are shown in Table 2 . The maximum relative error obtained in this case is $3.27 \%$ at $20 \mathrm{~cm}$ distance; as in the previous case, this may be because the soil properties are not uniform and change when approaching the interface, one of these properties is the volume fraction of each substance.

The results of simulation properly fit to the experimental data obtained in the laboratory. Therefore, the application of the Equation 12 and 15 within the heat transfer model for green roofs is suitable. 


\begin{tabular}{|c|c|c|c|c|c|c|c|c|c|}
\hline \multicolumn{10}{|c|}{ Experimental data } \\
\hline - & $20 \mathrm{~cm}$ & $\circ$ & $15 \mathrm{~cm}$ & $\Delta$ & $10 \mathrm{~cm}$ & $\nabla$ & $5 \mathrm{~cm}$ & 4 & $0 \mathrm{~cm}$ \\
\hline \multicolumn{10}{|c|}{ Simulated data } \\
\hline$*$ & $20 \mathrm{~cm}$ & $\diamond$ & $15 \mathrm{~cm}$ & (1) & $10 \mathrm{~cm}$ & - & $5 \mathrm{~cm}$ & $\star$ & $0 \mathrm{~cm}$ \\
\hline
\end{tabular}

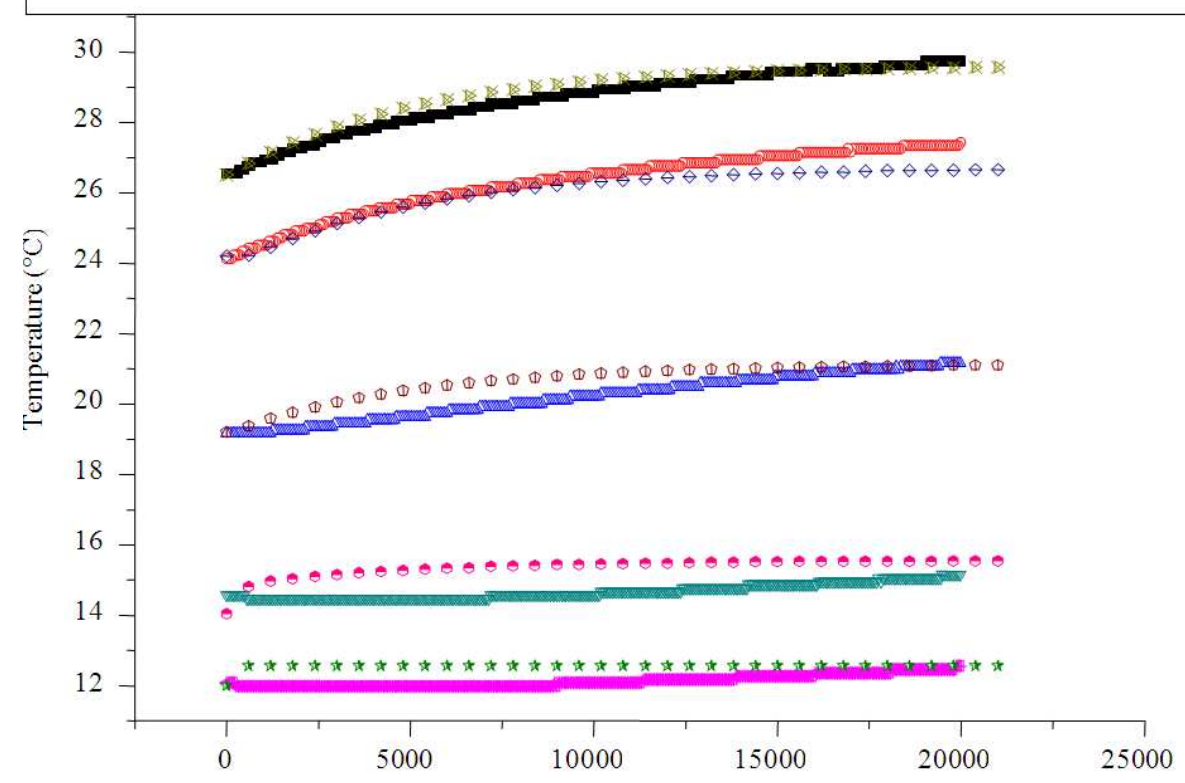

Fig. 4. Comparison of experimental data (lines) with simulated data (dots) at different heights (laboratory temperature $35^{\circ} \mathrm{C}$ )

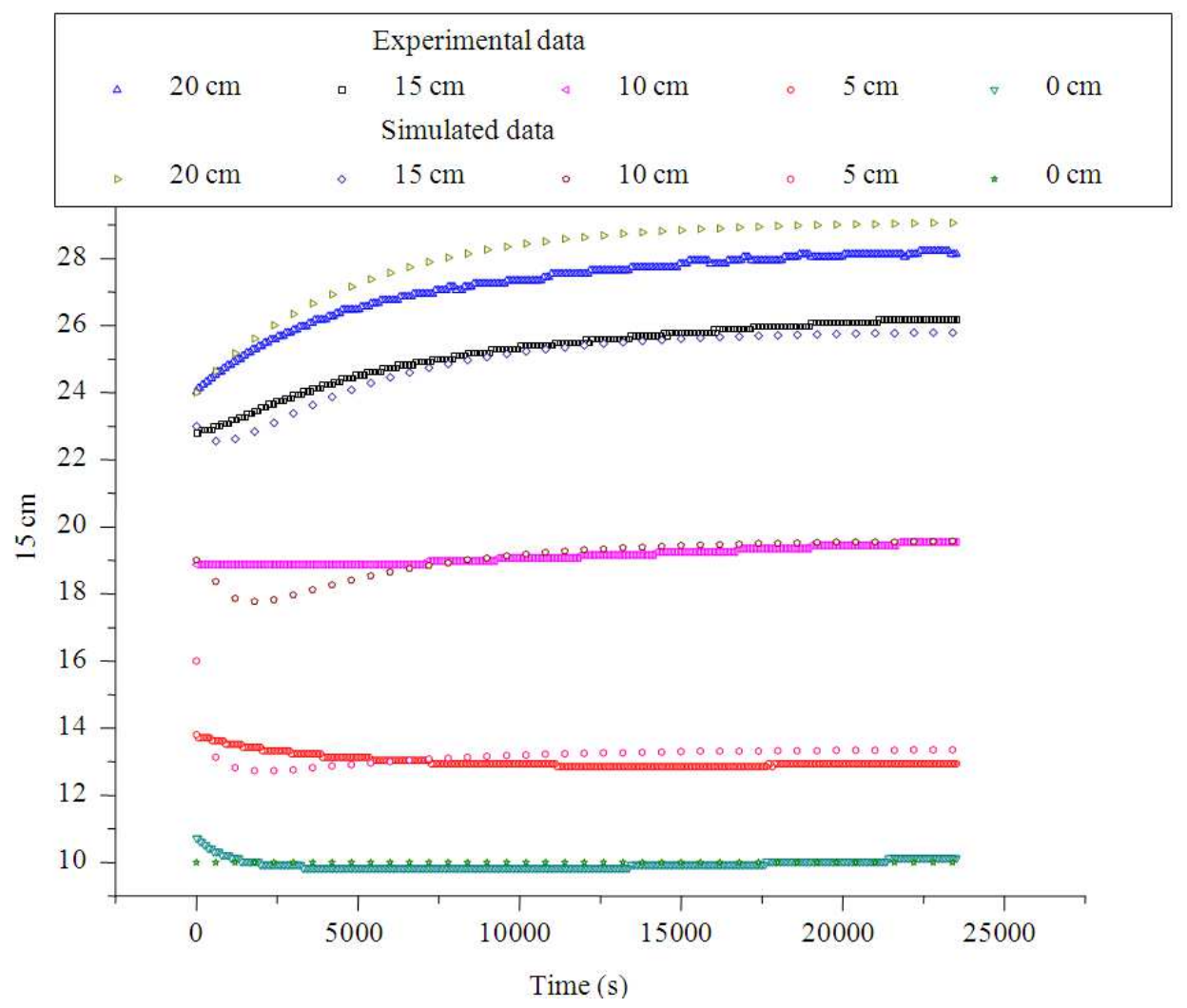

Fig. 5. Comparison of experimental data (lines) with simulated data (dots) at different heights (laboratory temperature $32^{\circ} \mathrm{C}$ ) 
Table 1. Comparing the experimental data with the results of simulation (first case)

\begin{tabular}{|c|c|c|c|c|c|}
\hline \multirow[b]{2}{*}{ Temperature } & \multicolumn{5}{|c|}{ Distance (cm) } \\
\hline & 20 & 15 & 10 & 5 & 0 \\
\hline Experimental $\left({ }^{\circ} \mathrm{C}\right)$ & 29.730 & 27.4400 & 21.160 & 15.160 & 12.560 \\
\hline Simulation $\left({ }^{\circ} \mathrm{C}\right)$ & 29.560 & 23.6500 & 21.100 & 15.550 & 12.560 \\
\hline Relative error (\%) & 0.5718 & 13.8120 & 0.2836 & 2.5726 & 0.0000 \\
\hline
\end{tabular}

Table 2. Comparing the experimental data with the results of simulation (second case)

\begin{tabular}{|c|c|c|c|c|c|}
\hline \multirow[b]{2}{*}{ Temperature } & \multicolumn{5}{|c|}{ Distance $(\mathrm{cm})$} \\
\hline & 20 & 15 & 10 & 5 & 0 \\
\hline Experimental $\left({ }^{\circ} \mathrm{C}\right)$ & 28.130 & 26.170 & 19.540 & 12.940 & 10.120 \\
\hline Simulation $\left({ }^{\circ} \mathrm{C}\right)$ & 29.050 & 25.790 & 19.570 & 13.350 & 10.000 \\
\hline Relative error $(\%)$ & 3.2705 & 1.4520 & 0.1535 & 2.1685 & 0.1858 \\
\hline
\end{tabular}

\section{Discussion}

With the application of equations for porous materials it is possible to describe the heat transfer at the layers that make up green roofs. These equations have the advantage that they are easily applicable and contain the most important effects due to the properties of each material composing the layer under study.

Important effects on the canopy can not be taken into account if equations for porous media are not used. Among these effects we could have the shade provided by the canopy plus a change in the effective properties of the green layer.

Moreover it is clear that a higher density of plants in the green layer causes that the effective properties tend towards plant values, while properties for a lower density of plants will be more similar to those of air, similar behavior is also observed in the soil layer.

Likewise, through the right approach of boundary conditions it could be included important effects of heat sources in the soil layer.

\section{Conclusion}

In this study was proposed a new mathematical model to describe the heat transfer through green roofs. The main contribution is that the equations considering some layers of green roof consist of porous materials. The inclusion of porous media equations in the model was compared with experimental data. Good agreement between simulation and experiment exists for several experimental scenarios in a controlled environment laboratory.

Comparing the experimental data with the data obtained using the mathematical model simulation indicates that both curves show the same tendency.

On the other hand, a boundary condition is provided to integrate the heat sources involved in the model.

The mathematical model presented in this study can be used to compare the heat transfer through a green roof and a conventional roof in order to calculate the energy savings.

\section{Apendice A}

In this section it is presented the method used to move from the local-instantaneous formulation, for each of the phases in soil layer, to an equation valid for both phases. From the local instant formulation for earth and water vapor have:

$$
\begin{aligned}
& (\rho C p)_{\ell} \frac{\partial T_{\ell}}{d t}=k_{\ell} \nabla^{2} T_{\ell}+q^{\prime \prime \prime} \\
& (\rho C p)_{w} \frac{\partial T_{w}}{d t}=k_{w} \nabla^{2} T_{w}+q^{\prime \prime \prime}
\end{aligned}
$$

The Equation A.1 and A.2 consider the heat transfer only by conduction, as the speed of the fluid phase is approximately zero.

On the other hand, average temperature of the land in the soil layer is given by Equation A.3:

$$
\left\langle T_{\ell}\right\rangle=\frac{1}{V} \int_{V_{\ell}} T_{\ell} d V
$$

where, $V$ is the total volume and $V_{\ell}$ is the land volume. The average temperature of land on land is given by:

$$
\left\langle T_{\ell}\right\rangle^{\ell}=\frac{1}{V_{\ell}} \int_{V_{\ell}} T_{\ell} d V
$$

The Equation A.4 and A.5 are related by volume fraction:

$\varepsilon_{p}=\frac{\frac{1}{V} \int_{V_{\ell}} T_{\ell} d V}{\frac{1}{V_{\ell}} \int_{V_{\ell}} T_{\ell} d V}$

It averaging the left side of Equation A.1 and (A.6) is: 


$$
\left\langle\frac{\partial T_{\ell}}{d t}\right\rangle=\frac{1}{V} \int_{V} \frac{\partial T_{\ell}}{d t} d V
$$

By applying Leibniz's theorem to Equation 6 we have Equation (A.7):

$$
\left\langle\frac{\partial T_{\ell}}{\partial t}\right\rangle=\frac{\partial\left\langle T_{\ell}\right\rangle}{\partial t}+\frac{1}{V} \int_{A_{\ell w}} T_{\ell} w \cdot n_{\ell w} d A
$$

where, $A_{f w}$ is the interfacial area between land and water, $w$ is expansion volumetric coefficient for this case is zero and $n_{t w}$ is the unitary normal vector. Therefore the Equation A.7 can be written as:

$$
\begin{aligned}
\left\langle\frac{\partial T_{\ell}}{\partial t}\right\rangle & =\frac{\partial\left\langle T_{\ell}\right\rangle}{\partial t} \\
\text { Or: } & \\
\left\langle\frac{\partial T_{\ell}}{\partial t}\right\rangle & =\varepsilon_{\ell} \frac{\partial\left\langle T_{\ell}\right\rangle^{\ell}}{\partial t}
\end{aligned}
$$

Applying a similar treatment to the first term on the right side of Equation A1:

$$
\begin{aligned}
& \nabla^{2} T_{\ell}=\nabla \cdot\left(\nabla T_{\ell}\right) \\
& \left\langle\nabla \cdot\left(\nabla T_{\ell}\right)\right\rangle=\frac{1}{V} \int_{V} \nabla \cdot\left(\nabla T_{\ell}\right) d V \\
& \left\langle\nabla \cdot\left(\nabla T_{\ell}\right)\right\rangle=\nabla \cdot\left\langle\nabla T_{\ell}\right\rangle+\frac{1}{V} \int_{A_{\ell w}}\left(\nabla T_{\ell}\right) \cdot n_{\ell w} d A \\
& \left\langle\nabla \cdot\left(\nabla T_{\ell}\right)\right\rangle= \\
& \nabla \cdot\left\{\nabla\left\langle T_{\ell}\right\rangle+\frac{1}{V} \int_{A_{\ell w}} T_{\ell} \cdot n_{\ell w} d A\right\} \\
& \quad+\frac{1}{V} \int_{A_{\ell w}}\left(\nabla T_{\ell}\right) \cdot \vec{n}_{\ell w} d A
\end{aligned}
$$

$$
\begin{aligned}
&\left\langle\nabla \cdot\left(\nabla T_{\ell}\right)\right\rangle=\nabla^{2}\left\langle T_{\ell}\right\rangle+ \\
& \nabla \cdot\left\{\frac{1}{V} \int_{A_{\ell w}} T_{\ell} \cdot n_{\ell w} d A\right\}+ \\
& \frac{1}{V} \int_{A_{\ell w}}\left(\nabla T_{\ell}\right) \cdot \vec{n}_{\ell w} d A
\end{aligned}
$$

So you rewriting Equation A.1, we have Equation (A.15):

$$
\begin{aligned}
(\rho C p)_{\ell} \varepsilon_{\ell} \frac{\partial\left\langle T_{\ell}\right\rangle^{\ell}}{\partial t}= & \\
k_{\ell}\left(\begin{array}{l}
\nabla^{2}\left\langle T_{\ell}\right\rangle+\nabla \cdot\left\{\frac{1}{V} \int_{A_{\ell w}} T_{\ell} \cdot n_{\ell w} d A\right\} \\
+\frac{1}{V} \int_{A_{\ell w}}\left(\nabla T_{\ell}\right) \cdot \vec{n}_{\ell w} d A
\end{array}\right) & +\left\langle q^{\prime \prime \prime}\right\rangle
\end{aligned}
$$

Defining an interfacial area density as:

$a_{\ell w}=\frac{A_{\ell w}}{V}$

Can rewrite the Equation A.15 as:

$$
\begin{aligned}
(\rho C p)_{\ell} \varepsilon_{\ell} \frac{\partial\left\langle T_{\ell}\right\rangle^{\ell}}{\partial t} & = \\
k_{\ell} \varepsilon_{\ell} \nabla^{2}\left\langle T_{\ell}\right\rangle^{\ell} & +k_{\ell w} \varepsilon_{w} \nabla^{2}\left\langle T_{w}\right\rangle^{w} \\
& +q_{\ell w} a_{\ell w}+\varepsilon_{\ell}\left\langle q^{\prime \prime \prime}\right\rangle^{\ell}
\end{aligned}
$$

To apply the same procedure to Equation 2 we have:

$$
\begin{aligned}
&(\rho C p)_{w} \varepsilon_{w} \frac{\partial\left\langle T_{w}\right\rangle^{w}}{\partial t}= \\
& k_{w} \varepsilon_{w} \nabla^{2}\left\langle T_{w}\right\rangle^{w}+k_{w \ell} \varepsilon_{\ell} \nabla^{2}\left\langle T_{\ell}\right\rangle^{\ell} \\
&+q_{w \ell} a_{w \ell}
\end{aligned}
$$

If is considering thermodynamic equilibrium, i.e., $\left\langle T_{\ell}\right\rangle^{\ell}=\left\langle T_{w}\right\rangle^{w}=\langle T\rangle$ and adding the Equation A.16 and A. 17 we have:

$$
\begin{aligned}
& \left(\rho_{\ell} C p_{\ell} \varepsilon_{\ell}+\rho_{w} C p_{w} \varepsilon_{w}\right) \frac{\partial\langle T\rangle}{\partial t}= \\
& \left(k_{\ell} \varepsilon_{\ell}+k_{w} \varepsilon_{w}\right) \nabla^{2}\langle T\rangle+k_{\ell w} \varepsilon_{\ell} \nabla^{2}\left\langle T_{w}\right\rangle^{w} \\
& +k_{w \ell} \varepsilon_{w} \nabla^{2}\left\langle T_{\ell}\right\rangle^{\ell}+q_{\ell w} a_{\ell w}+q_{w \ell} a_{w \ell}+\varepsilon_{\ell}\left\langle q^{\prime \prime \prime}\right\rangle^{\ell}
\end{aligned}
$$

Defining the following properties:

$$
\begin{aligned}
& q_{\ell w}=\vartheta\left(\left\langle T_{\ell}\right\rangle^{\ell}-\left\langle T_{\ell}\right\rangle^{\ell}\right) \\
& K_{s}=\left(k_{\ell} \varepsilon_{\ell}+k_{w} \varepsilon_{w}\right) \\
& (\rho C p)_{s}=\left(\rho_{\ell} C p_{\ell} \varepsilon_{\ell}+\rho_{w} C p_{w} \varepsilon_{w}\right)
\end{aligned}
$$

Equation A.20 and A.21 are the effective properties of the layer of soil. Moreover it is considered that: 


$$
q_{\ell w} a_{\ell w}=-q_{w \ell} a_{w \ell}
$$

Hence substituting Equation A.19-A.21 into Equation A.18 we have Equation (A.22):

$$
(\rho C p)_{s} \frac{\partial\langle T\rangle}{\partial t}=K_{s} \nabla^{2}\langle T\rangle+\varepsilon_{\ell}\left\langle q^{\prime \prime \prime}\right\rangle^{\ell}
$$

\section{Acknowledgement}

I would like to thank the CONACyT doctoral grant Dr. J.J. Ambriz-García for his support in the experiments at his research lab "Controlled Environment Laboratory (CEL)" of the Universidad Autónoma MetropolitanaIztapalapa.

\section{Funding Information}

The research was funded thanks to the CONACyT doctoral grant to the first author.

\section{Author's Contributions}

The first author is completing his doctoral studies and the rest of the coauthors are part of his doctoral committee, in this sense all authors contributed in equal way in this publication.

Sergio Quezada-García: Performed all experiments, coordinated the data-analysis and contributed to the writing of the manuscript.

Manuela Azucena Escobedo-Izquierdo: Designed the research plan and organized the study.

Juan José Ambriz-García: Participated in all experiments.

Rodolfo Vázquez-Rodriguez: Participated coordinated the data-analysis and contributed to the writing of the manuscript.

Diego Morales-Ramírez: Designed the research plan and organized the study.

\section{Ethics}

We do not have any ethical issues.

\section{References}

Arroyo-Cabañas, F.G., J.E. Aguillón-Martínez, J.J. Ambríz-García and G. Canizal, 2009. Electric energy saving potential by substitution of domestic refrigerators in Mexico. Energy Policy, 371: $4737-$ 4742. DOI: 10.1016/j.enpol.2009.06.032

Ayata, T., P.C. Tabares-Velasco and J. Srebric, 2011. An investigation of sensible heat fluxes at a green roof in a laboratory setup. Building Environ., 46: 1851-1861. DOI: 10.1016/j.buildenv.2011.03.006
Berndtsson, J.C., L. Bengtsson and K. Jinnob, 2009. Runoff water quality from intensive and extensive vegetated roofs. Ecol. Eng., 35: 369-380.

Castleton, H.F., V. Stovin, S.B.M. Beck and J.B. Davison, 2010. Green roofs; Building energy savings and the potential for retrofit. Energy Build., 42: 1582-1591. DOI:10.1016/j.enbuild.2010.05.004

Chan, A.L.S. and T.T. Chow, 2013. Energy and economic performance of green roof system under future climatic conditions in Hong Kong. Energy Build., 64: 182-198. DOI: 10.1016/j.enbuild.2013.05.015

Clark, C., P. Adriaens and B. Talbot, 2008. Green roof valuation: A probabilistic economic analysis of environmental benefits. Environ. Sci. Tech., 42: 2155-2161. DOI: 10.1021/es0706652

Deardorff, J.W., 1978. Efficient prediction of ground surface temperature and moisture, with inclusion of a layer of vegetation. J. Geoph. Res., 83: 1889-903. DOI: 10.1029/JC083iC04p01889

Del Barrio, E.P., 1998. Analysis of the green roofs cooling potential in buildings. Energy Build., 27: 179-193. DOI: 10.1016/S0378-7788(97)00029-7

Denardo, J., 2003. Green roof mitigation of stormwater and energy usage. MS thesis, Dept. of Horticulture, Pennsylvania State University, PA.

Espinosa-Paredes, G., 2010. Instantaneous equations for multiphase flow in porous media without lengthscale restrictions using a non-local averaging volume. Nuclear Eng. Design, 240: 1160-1185. DOI: $10.1016 /$ j.nucengdes.2010.01.018

Espinosa-Paredes, G., 2012. A derivation of the nonlocal volumen-averaged equations for two-phase flow transport. Sci. Tech. Nuclear Install., 2012: 8-8. DOI: $10.1155 / 2012 / 890815$

Espinosa-Paredes, G., V. Castillo-Jiménez, L.E. Herranz-Puebla and R. Vázquez-Rodríguez, 2013. Analysis of the interfacial heat transfer process in a pebble fuel. Prog. Nuclear Energy, 65: 15-31. DOI: $10.1016 /$ j.pnucene.2013.01.002

Feng, C., Q. Meng and Y. Zhang, 2010. Theoretical and experimental analysis of the energy balance of extensive green roofs. Energy Build., 42: 959-965. DOI: $10.1016 /$ j.enbuild.2009.12.014

Hong, T., J. Kim and C. Koo, 2012. LCC and LCCO2 analysis of green roofs in elementary schools with energy saving measures. Energy Build., 45: 229239. DOI: $10.1016 /$ j.enbuild.2011.11.006

Jensen, M.E., R.D. Burman and R.G. Allen, 1990. Evapotranspiration and irrigation water requirements. 1st Edn., American Society of Civil Engineers, New York, pp: 332.

Jim, C.Y. and S.W. Tsang, 2011. Modeling the heat diffusion process in the abiotic layers of green roofs. Energy Build., 43: 1341-1350. DOI: 10.1016/j.enbuild.2011.01.012 
Kosareo, L. and R. Ries, 2007. Comparative environmental life cycle assessment of green roofs. Build. Environ., 42: 2606-2613. DOI: 10.1016/j.buildenv.2006.06.019

Kumar, R. and S.C. Kaushik, 2005. Performance evaluation of green roof and shading for thermal protection of buildings. Build. Environ., 40: 15051511. DOI: 10.1016/j.buildenv.2004.11.015

Li, J.F., O.W.H. Wai, Y.S. Li, J.M. Zhan and Y.A. Ho et al., 2010. Effect of green roof on ambient CO2 concentration. Build. Environ., 45: 2644-2651. DOI: 10.1016/j.buildenv.2010.05.025

Lin, C.Y., F. Chen, J.C. Huang, W.C. Chen and Y.A. Liou et al., 2008. Urban heat island effect and its impact on boundary layer development and land-sea circulation over northern Taiwan. Atmospheric Environ., 42: 5635-5649.

DOI: 10.1016/j.atmosenv.2008.03.015

Madre, F., A. Vergnes, N. Machon and P. Clergeau, 2013. A comparison of 3 types of green roof as habitats for arthropods. Ecol. Eng., 57: 109-117. DOI: $10.1016 /$ j.ecoleng.2013.04.029

Meng, Q. and W. Hu, 2005. Roof cooling effect with humid porous medium. Energy Build., 37: 1-9. DOI: 10.1016/j.enbuild.2003.11.004

Mentens, J., D. Raes and M. Hermy, 2006. Green roofs as a tool for solving the rainwater runoff problem in the urbanized 21 st century?. Landscape Urban Plann., 77: 217-226.

DOI: $10.1016 /$ j.landurbplan.2005.02.010

Niachou, A., K. Papakonstantinou, M. Santamouris, A. Tsangrassoulis and G. Mihalakakou, 2001. Analysis of the green roof thermal properties and investigation of its energy performance. Energy Build., 33: 719-729.

DOI: $10.1016 / \mathrm{S} 0378-7788(01) 00062-7$

Onmura, S., M. Matsumoto and S. Hokoi, 2001. Study on evaporative cooling effect of roof lawn gardens. Energy Build., 33: 653-666. DOI: $10.1016 / \mathrm{S} 0378-7788(00) 00134-1$

Renterghem, T.V. and D. Botteldooren, 2009. Reducing the acoustical façade load from road traffic with green roofs. Build. Environ., 44: 1081-1087. DOI: 10.1016/j.buildenv.2008.07.013

Sailor, D.J. and M. Hagos, 2012. An updated and expanded set of thermal property data for green roof growing media. Energy Build., 43: 2298-2303. DOI: $10.1016 /$ j.enbuild.2011.05.014

Sailor, D.J. 2008. A green roof model for building energy simulation programs. Energy Build., 40: 1466-1478. DOI: 10.1016/j.enbuild.2008.02.001

Saiz, S., C. Kennedy, B. Bass and K. Pressnail, 2006. Comparative life cycle assessment of standard and green roofs. Environ. Sci. Tech., 40: 4312-4316. DOI: $10.1021 / \mathrm{es} 0517522$
Santamouris, M., 2012. Cooling the cities-a review of reflective and green roof mitigation technologies to fight heat island and improve comfort in urban environments. Solar Energy, 103: 682-70. DOI: $10.1016 /$ j.solener.2012.07.003

Speak, A.F., J.J. Rothwell, S.J. Lindley and C.L. Smith, 2013. Rainwater runoff retention on an aged intensive green roof. Sci. Total Environ., 461-462: 28-38. DOI: 10.1016/j.scitotenv.2013.04.085

Stovin, V., G. Vesuviano and H. Kasmin, 2012. The hydrological performance of a green roof test bed under UK climatic conditions. J. Hydrol., 415: 148161). DOI: 10.1016/j.jhydrol.2011.10.022

Tabares-Velasco, P.C. and J. Srebric, 2009. The role of plants in the reduction of heat flux through green roofs: Laboratory experiments. ASHRAE Transactions.

Takebayashi, H. and M. Moriyama, 2007. Surface heat budget on green roof and high reflection roof for mitigation of urban heat island. Build. Environ., 42: 2971-2979. DOI: 10.1016/j.buildenv.2006.06.017

Theodosiou, T.G., 2003. Summer period analysis of the performance of a planted roof as a passive cooling technique. Energy Build., 35: 909-917. DOI: $10.1016 / \mathrm{S} 03787788(03) 00023-9$

Weng, Q. and S. Yang, 2004. Managing the adverse thermal effects of urban development in a densely populated Chinese city. J. Environ. Manag., 70: 145156. DOI: 10.1016/j.jenvman.2003.11.006

Wong, J.K.W. and L.S.K. Lau, 2013. From the 'urban heat island' to the 'green island'? A preliminary investigation into the potential of retrofitting green roofs in Mongkok district of Hong Kong. Habitat Int., 39: 25-35. DOI: 10.1016/j.habitatint.2012.10.005

Wong, N.H. and Y. Chen, 2005. Study of green areas and urban heat island in a tropicalcity. Habitat Int., 29: 547-558. DOI: 10.1016/j.habitatint.2004.04.008

Wong, N.H., Y. Chen, C.L. Ong and A. Sia, 2003. Investigation of thermal benefits of rooftop garden in the tropical environment. Build. Environ., 38: 261-270. DOI: 10.1016/S0360-1323(02)00066-5

Yang, J., Q. Yu and P. Gong, 2008. Quantifying air pollution removal by green roofs in Chicago. Atmospheric Environ., 42: 7266-7273. DOI: 10.1016/j.atmosenv.2008.07.003

Zinzi, M. and S. Agnoli, 2012. Cool and green roofs. An energy and comfort comparison between passive cooling and mitigation urban heat island techniques for residential buildings in the Mediterranean region. Energy Build., 55: 66-76. DOI: $10.1016 /$ j.enbuild.2011.09.024 